\title{
Taurolidine promotes cell apoptosis by enhancing GRIM-19 expression in liver cancer
}

\author{
FEIFEI LI ${ }^{1,2}$, JIANNI QI ${ }^{2,3}$, CHENGYONG QIN $^{1,2}$, ZHAOQING FU $^{4}$ and WANHUA REN ${ }^{1,2}$ \\ ${ }^{1}$ Department of Infectious Diseases, Shandong Provincial Hospital Affiliated to Shandong University; \\ ${ }^{2}$ Shandong Provincial Engineering and Technological Research Center for Liver Diseases Prevention and Control, \\ Jinan, Shandong 250021; ${ }^{3}$ Central Laboratory, Shandong Provincial Hospital Affiliated to Shandong University; \\ ${ }^{4}$ Department of Thoracic Surgery, Shandong University of Traditional Chinese Medicine Affiliated Hospital, \\ Jinan, Shandong 250014, P.R. China
}

Received March 22, 2018; Accepted September 10, 2018

DOI: $10.3892 /$ or.2018.6711

\begin{abstract}
Taurolidine (TRD) is a substance derived from the amino sulfonic acid taurine, which was originally used to treat peritonitis and catheter-associated bloodstream infections, due to its antimicrobial and anti-inflammatory properties. A recent study reported the anticancer function of TRD in malignant tumors; however, the effects and mechanisms of TRD in liver cancer remain unclear. The present study aimed to investigate the effects and mechanism of TRD treatment on human liver cancer cells. The viability and apoptosis of liver cancer cells were evaluated using the MTT assay and flow cytometry. Subsequently, small interfering RNA (siRNA) was used to knock down the expression of gene associated with retinoid-interferon-induced mortality-19 (GRIM-19), after which, reverse transcription-quantitative polymerase chain reaction was used to detect the mRNA expression levels of GRIM-19, whereas immunofluorescence was used to analyze the location of GRIM-19. Furthermore, western blotting was performed to detect the protein expression levels
\end{abstract}

Correspondence to: Dr Wanhua Ren, Department of Infectious Diseases, Shandong Provincial Hospital Affiliated to Shandong University, 324 Jing Wu Road, Jinan, Shandong 250021, P.R. China E-mail: wanhuaren@126.com

Dr Zhaoqing Fu, Department of Thoracic Surgery, Shandong University of Traditional Chinese Medicine Affiliated Hospital, 16369 Jingshi Road, Jinan, Shandong 250014, P.R. China

E-mail: szyfzq@126.com

Abbreviations: GRIM-19, gene associated with retinoidinterferon-induced mortality-19; TRD, taurolidine; RT-qPCR, reverse transcription-quantitative polymerase chain reaction; siRNA, small interfering RNA; STAT3, signal transducer and activator of transcription 3; p-STAT3, phosphorylated-signal transducer and activator of transcription protein 3; FBS, fetal bovine serum; DMSO, dimethyl sulfoxide

Key words: taurolidine, GRIM-19, p-STAT3, apoptosis of GRIM-19, cyclin D1, signal transducer and activator of transcription 3 (STAT3), phosphorylated (p)-STAT3, B-cell lymphoma 2 (Bcl-2) and Bcl-2-associated X protein (Bax). The STAT3 pathway was inhibited using niclosamide. The results revealed that TRD reduced the viability of liver cancer cells and induced apoptosis at higher frequencies. In addition, the expression levels of GRIM-19 were increased in a time- and dose-dependent manner following TRD treatment. Alongside GRIM-19 upregulation, the expression levels of Bax were increased, whereas those of cyclin D1, Bcl-2 and p-STAT3 were decreased. Furthermore, following GRIM-19 knockdown, the effects of TRD on the viability and apoptosis of HepG2 cells, and the expression of downstream target genes (including cyclin D1, STAT3, p-STAT3, Bcl-2 and Bax) were reversed. Conversely, treatment with a p-STAT3 inhibitor had an inverse effect on the expression of these genes but did not affect GRIM-19 expression compared with the TRD group. These results indicated that TRD may contribute to cell apoptosis by inducing GRIM-19 expression and deactivating the STAT3 signaling pathway in liver cancer cells.

\section{Introduction}

Liver cancer is one of the most common causes of cancerassociated mortality worldwide, particularly in China (1). Hepatocellular carcinoma accounts for $70-85 \%$ of all liver cancer cases (2). There are currently several treatment options for liver cancer; however, none have been shown to be a cure-all, with regards to recurrence, patient survival and longevity (3). Patients with early-stage liver cancer can be treated with surgery, which may involve removal of part of the liver or transplantation; the 5-year survival rate in these cases often exceeds $70 \%$. However, the majority of cases are not suitable for surgical treatment; the overall 5-year survival rate in these cases is $\sim 15 \%$ (4). Until 2017, there was no systemic treatment option for patients with advanced liver cancer. Therefore, it is important to investigate the molecular mechanisms underlying liver carcinogenesis, and to identify novel approaches that can effectively inhibit liver cancer cell growth and metastasis.

Taurolidine (TRD) is a substance derived from the amino sulfonic acid taurine, which was originally used to treat 
peritonitis and catheter-associated infections (5). Previous studies have revealed that TRD inhibits proliferation of cancer cells and induces the differentiation of malignant cells, including glioblastoma $(6,7)$, melanoma $(8,9)$, mesothelioma $(10,11)$, colon carcinoma $(12,13)$, squamous cell esophageal carcinoma (14) and sarcoma cell lines $(15,16)$. However, the effect and mechanism of TRD in liver cancer remain to be elucidated.

Gene associated with retinoid-interferon-induced mortality-19 (GRIM-19) is located on human chromosome 19p-13.1 and encodes a 16-kD protein comprising 144 amino acids (17). GRIM-19 serves an important role in the mitochondrial respiratory chain (18). Our previous study (19) revealed that GRIM-19 is an important regulator of tumor cell survival. Notably, downregulation of GRIM-19 and hyperactivation of phosphorylated (p)-signal transducer and activator of transcription 3 (STAT3) expression in liver cancer lesions are closely correlated with increased histological grading in liver cancer $(19,20)$. Favorable pharmacokinetic and safety data have been reported for TRD following systemic application in healthy volunteers (21), as well as in patients with locally advanced gastric carcinoma and glioblastoma (22-24). However, the role of TRD in the induction of cell apoptosis remains to be fully elucidated. The mitochondria-dependent pathway $(7,15,25-27)$ and the death receptor-associated pathway have been reported to be associated with TRD-induced apoptosis $(14,16,27,28)$. However, it is not clear whether TRD can induce liver cancer cell apoptosis; therefore, the potential mechanism requires further exploration.

In the present study, the effects of TRD treatment on GRIM-19, cyclin D1, STAT3, p-STAT3, B-cell lymphoma 2 (Bcl-2) and $\mathrm{Bcl}-2$-associated $\mathrm{X}$ protein (Bax) expression, and on the apoptosis of liver cancer cells, were investigated in vitro. The results indicated that treatment with TRD induced liver cancer cell apoptosis in a dose-dependent manner, which was associated with an increase in GRIM-19 expression and deactivating the STAT3 signaling pathway.

\section{Materials and methods}

Cell lines and transfection. HepG2 and SNU-423 human liver cancer cell lines were obtained from the Shanghai Preservation Center Cell Bank (Shanghai, China). HepG2 cells were cultured in Dulbecco's modified Eagle's medium (Gibco; Thermo Fisher Scientific, Inc., Waltham, MA, USA), whereas SNU-423 cells were cultured in Roswell Park Memorial Institute 1640 medium (Gibco; Thermo Fisher Scientific, Inc.), both media were supplemented with $10 \%$ fetal bovine serum (FBS; Gibco; Thermo Fisher Scientific, Inc.), $100 \mathrm{U} / \mathrm{ml}$ penicillin and $100 \mu \mathrm{g} / \mathrm{ml}$ streptomycin (Thermo Fisher Scientific, Inc.) at $37^{\circ} \mathrm{C}$ in an atmosphere containing $5 \% \mathrm{CO}_{2}$. Small interfering RNA (siRNA) duplex oligoribonucleotides targeting the coding region of GRIM-19 were obtained from Thermo Fisher Scientific, Inc. HepG2 and SNU-423 cells $\left(10^{5}\right.$ cells/well) were transfected with control siRNA (5'-UUCUCCGAACGUGUCACGUTT-3', $50 \mathrm{nM}$ ) or specific GRIM-19 siRNA (5'-GCUUCAUGUGGUACA CGUATT-3', 50 nM) using Lipofectamine ${ }^{\circledR} 2000$ (Thermo Fisher Scientific, Inc., Waltham, MA, USA), according to the manufacturer's protocol. The culture medium was replaced after $6 \mathrm{~h}$ of incubation. Subsequently, $48 \mathrm{~h}$ post-transfection, the cells were collected. GRIM-19 knockdown cells were pretreated with niclosamide (p-STAT3 inhibitor, $10 \mu \mathrm{M}$; 50-65-7; Selleck Chemicals, Houston, TX, USA) for $30 \mathrm{~min}$, after which, $100 \mu \mathrm{M}$ TRD (Santa Cruz Biotechnology, Inc., Dallas, TX, USA) was added for $24 \mathrm{~h}$.

MTT assay. The effects of treatment with TRD on HepG2 and SNU-423 cell viability were measured using the MTT assay. Cells $\left(10^{3}\right.$ cells/well) were cultured in 96 -well plates overnight and were treated with TRD at various concentrations $(10,50,100$ and $200 \mu \mathrm{M})$ for $0,12,24,48$ or $72 \mathrm{~h}$ at $37^{\circ} \mathrm{C}$ in an atmosphere containing $5 \% \mathrm{CO}_{2}$. During the last $4 \mathrm{~h}$ of culture, the cells in each well were exposed to $20 \mu \mathrm{l}$ MTT $(5 \mathrm{mg} / \mathrm{ml}$; Merck KGaA, Darmstadt, Germany). The generated formazan in each well was then dissolved in $150 \mu$ l dimethyl sulfoxide (DMSO) and the absorbance was measured at $490 \mathrm{~nm}$ using a microplate reader, as previously described (29).

Flow cytometry. HepG2 cells were treated with various concentrations of TRD $(50,100$ and $200 \mu \mathrm{M})$ and SNU-423 cells were treated with $200 \mu \mathrm{M}$ TRD for 24 or $48 \mathrm{~h}$ at $37^{\circ} \mathrm{C}$. In addition, GRIM-19 knockdown cells were treated with $100 \mu \mathrm{M}$ TRD for $24 \mathrm{~h}$ at $37^{\circ} \mathrm{C}$. Cells $\left(3 \times 10^{5}\right.$ cells/well $)$ were then transferred to a tube in which Annexin $\mathrm{V}(5 \mu \mathrm{l})$ and propidium iodide (5 $\mu$ l) (APOAF; Sigma-Aldrich; Merck KGaA, Darmstadt, Germany) were added, and the cells were incubated for $30 \mathrm{~min}$ at $37^{\circ} \mathrm{C}$. Subsequently, the percentages of apoptotic cells in the different groups were determined by flow cytometry, using the BD FACSCelesta ${ }^{\mathrm{TM}}$ flow cytometer (BD Biosciences, San Jose, CA, USA). Data were analysed with FCS Express 4 (De Novo Software, Los Angeles, CA, USA). In addition, some cells were stained with trypan blue (ab233465; Abcam, Hong Kong, China) and surviving cells were counted under a microscope (Olympus IX51; Leeds Precision Instruments, Inc., Minneapolis, MN, USA) in a blinded manner. Cell survival rate was determined using the following equation: Survival rate $(\%)=$ number of unstained cells/total number of cells observed x 100. Survival rate of cells before TRD treatment exceeded $95 \%$ in all groups.

Immunofluorescence. HepG2 cells $\left(10^{5}\right.$ cells/slide) were cultured on glass cover slips in 24-well plates overnight, fixed with $4 \%$ paraformaldehyde (Merck KGaA) in PBS and washed with PBS. Following permeabilization, the glass cover slips were blocked with $1 \mathrm{mM} \mathrm{CaCl}, 1 \mathrm{mM} \mathrm{MgCl}_{2}, 5 \%$ normal goat serum (SL038; Beijing Solarbio Science \& Technology Co., Ltd., Beijing, China), 10\% FBS and 2\% bovine serum albumin ( $\mathrm{pH}$ 7.6, A8010; Beijing Solarbio Science \& Technology Co., Ltd.) in PBS and were incubated with mouse anti-human GRIM-19 antibody (1:1,000 dilution, ab110240; Abcam) at $4^{\circ} \mathrm{C}$ overnight. After washing with PBS containing $0.1 \%$ Triton $\mathrm{X}-100$, the glass cover slips were incubated with tetramethyl rhodamine isothiocyanate-conjugated secondary antibodies (1:100 dilution, BA1089; Boster Biological Technology, Pleasanton, CA, USA) for $30 \mathrm{~min}$ at $37^{\circ} \mathrm{C}$, followed by counterstaining with DAPI and mounting with Gel Mount ${ }^{\mathrm{TM}}$ Aqueous Mounting Medium (Merck KGaA). Images were acquired using a Leica ${ }^{\mathrm{TM}}$ fluorescence microscope equipped with a Leica ${ }^{\mathrm{TM}}$ camera (LEICA-DFC320; Leica Microsystems, Inc., Buffalo Grove, IL, USA). 
Western blot analysis. Cells ( $3 \times 10^{5}$ cells/well) were cultured in 24-well plates overnight, and were harvested and lysed with radioimmunoprecipitation assay buffer (R0020; Beijing Solarbio Science \& Technology Co., Ltd.). Protein concentrations were determined using the Bicinchoninic Acid Reagent (Thermo Fisher Scientific, Inc., after which, the cell lysates (30 $\mu \mathrm{g} /$ lane) were separated by $8-15 \%$ SDS-PAGE and transferred onto nitrocellulose membranes (GE Healthcare, Chicago, IL, USA). After blocking with 5\% non-fat dry milk (for GRIM-19, STAT3, Bcl-2, Bax and cyclin D1) or 5\% bovine serum albumin (for p-STAT3) in $10 \mathrm{mM}$ Tris- $\mathrm{Cl}(\mathrm{pH} 8.0)$, $150 \mathrm{mM} \mathrm{NaCl}$ and $0.05 \%$ Tween 20 for $1 \mathrm{~h}$, the membranes were incubated with various antibodies overnight at $4^{\circ} \mathrm{C}$. The bound antibodies were detected using horseradish peroxidase-conjugated immunoglobulin G secondary antibodies (1:5,000 dilutions, NA931 or NA9340; GE Healthcare) for $1 \mathrm{~h}$ at room temperature and visualized using enhanced chemiluminescence (GE Healthcare). The primary antibodies included mouse polyclonal anti-human GRIM-19 (1:1,000 dilution, ab110240; Abcam), mouse monoclonal anti-human STAT3 (1:5,000 dilution, ab119352; Abcam), rabbit monoclonal anti-human cyclin D1 (1:10,000 dilution, ab134175; Abcam), rabbit monoclonal anti-human Bcl-2 (1:1,000 dilution, ab32124; Abcam), rabbit monoclonal anti-human Bax (1:2,000 dilution, ab32503; Abcam), mouse monoclonal anti-human p-STAT3 (Tyr705) (1:2,000 dilution, \#4113; Cell Signaling Technology, Inc., Danvers, MA, USA), and anti- $\beta$-actin (1:1,000 dilution, sc-517582; Santa Cruz Biotechnology, Inc.). The levels of target protein expression relative to the control protein, $\beta$-actin, were analyzed by densitometric analysis using a detection system (Amersham Imager 600; GE Healthcare).

Reverse transcription-quantitative polymerase chain reaction (RT-qPCR). Total RNA was isolated from individual groups of cells using TRIzol ${ }^{\circledR}$ reagent (Invitrogen; Thermo Fisher Scientific, Inc.), according to the manufacturer's protocol. RNA was reverse transcribed into cDNA using the $\mathrm{RT}^{2}$ First Strand kit (330404; Qiagen, Inc., Valencia, CA, USA), according to the manufacturer's protocol. The expression levels of GRIM-19 mRNA transcripts relative to the $\beta$-actin control were determined by RT-qPCR using SYBR ${ }^{\circledR}$ Premix Ex Taq ${ }^{\mathrm{TM}}$ (Takara Biotechnology Co., Ltd., Dalian, China) and specific primers on the LC480 Real-time PCR system (Roche Applied Science, Penzberg, Germany). The thermocycling conditions were as follows: $95^{\circ} \mathrm{C}$ for $30 \mathrm{sec}$, followed by 40 cycles at $95^{\circ} \mathrm{C}$ for $5 \mathrm{sec}, 60^{\circ} \mathrm{C}$ for $30 \mathrm{sec}$ and $72^{\circ} \mathrm{C}$ for $30 \mathrm{sec}$, with a final extension step at $72^{\circ} \mathrm{C}$ for $5 \mathrm{~min}$. The primer sequences were as follows: GRIM-19 (116 bp), forward 5'-CATCGACTACAAACGGAA CTTG-3', reverse 5'-GCTCACGGTTCCACTTCATTA-3'; and $\beta$-actin (196 bp), forward 5'-TGACGTGGACATCCGCAA AG-3' and reverse 5'-CTGGAAGGTGGACAGCGAGG-3'. The data were quantified using the $2^{-\Delta \Delta \mathrm{Cq}}$ method $(30,31)$.

Statistical analysis. All statistical analyses were performed using SPSS 10.0 software (SPSS, Inc., Chicago, IL, USA). All data are expressed as the means \pm standard deviation. Multiple comparisons of means were determined using one- or two-way analysis of variance, followed by the post hoc Newman-Keuls test. $\mathrm{P}<0.05$ was considered to indicate a statistically significant difference.

\section{Results}

TRD significantly reduces HepG2 and SNU-423 cell viability and induces apoptosis. To determine the effects of TRD on liver cancer cell viability, HepG2 cells were treated with various concentrations of TRD $(10,50,100$ and $200 \mu \mathrm{M})$ for $0,12,24,48$ or $72 \mathrm{~h}$. Cell viability was then analyzed using the MTT assay. As shown in Fig. 1A, treatment with any concentration of TRD treatment for $12 \mathrm{~h}$, and with 10 and $50 \mu \mathrm{M}$ TRD at any time-point, did not significantly inhibit cell viability. However, TRD (100 and $200 \mu \mathrm{M})$ significantly inhibited cell viability in the 24 -h treatment group $(0.688 \pm 0.062$ vs. $0.997 \pm 0.055, \mathrm{P}<0.01 ; 0.652 \pm 0.074$ vs. $0.997 \pm 0.055, \mathrm{P}<0.01)$, the 48 -h treatment group $(0.987 \pm 0.037$ vs. $1.386 \pm 0.063, \mathrm{P}<0.01$; $0.817 \pm 0.045$ vs. $1.386 \pm 0.063, \mathrm{P}<0.01)$ and the 72 -h treatment group $(1.245 \pm 0.125$ vs. $1.772 \pm 0.116, \mathrm{P}<0.01 ; 1.034 \pm 0.108$ vs. $1.772 \pm 0.116, \mathrm{P}<0.01)$. These findings suggested that TRD inhibited HepG2 cell viability in a dose-dependent manner. Notably, the proliferation of HepG2 cells in the TRD group was significantly reduced, but not completely stopped; similar results were observed in the SNU-423 cells line.

Based on these results, HepG2 cells were then treated with various concentrations of TRD $(50,100$ and $200 \mu \mathrm{M})$ for 24 or $48 \mathrm{~h}$, in order to observe cell apoptosis by flow cytometry. The results revealed that TRD $(100$ and $200 \mu \mathrm{M})$ significantly increased cell apoptosis in the $24-$ and 48 -h groups $(\mathrm{P}<0.01)$. In addition, TRD treatment (100 and $200 \mu \mathrm{M})$ for $48 \mathrm{~h}$ significantly accelerated cell apoptosis compared with at $24 \mathrm{~h}$ $(\mathrm{P}<0.05 ; \mathrm{P}<0.01)$. TRD treatment $(50 \mu \mathrm{M})$ for 24 or $48 \mathrm{~h}$ had no effect on cell apoptosis $(\mathrm{P}=0.35 ; \mathrm{P}=0.28)$. These findings indicated that TRD induced apoptosis of HepG2 cells in a doseand time-dependent manner (Fig. 1B). Subsequently, SNU-423 cells were treated with TRD $(200 \mu \mathrm{M})$ for 24 and $48 \mathrm{~h}$, and cell apoptosis was detected by flow cytometric analysis. The results further confirmed that TRD induced apoptosis of liver cancer cells.

TRD upregulates GRIM-19 expression in HepG2 cells. GRIM-19 is a regulator of cell death, which is particularly associated with the stabilization and function of mitochondrial complex 1 (32). To understand the importance of GRIM-19 in TRD-induced apoptosis of liver cancer cells, HepG2 cells were treated with TRD at various concentrations $(50,100$ and $200 \mu \mathrm{M})$ for 24,48 or $72 \mathrm{~h}$. The expression levels of GRIM-19 were detected by western blotting. The results revealed that treatment with TRD $(100$ and $200 \mu \mathrm{M})$ significantly increased GRIM-19 protein expression in HepG2 cells in the $24-\mathrm{h}$ group $(1.57 \pm 0.12$ vs. $0.52 \pm 0.11, \mathrm{P}<0.01$; $2.35 \pm 0.31$ vs. $0.52 \pm 0.11, \mathrm{P}<0.01)$, in the 48 -h group $(1.99 \pm 0.22$ vs. $0.68 \pm 0.17, \mathrm{P}<0.01 ; 2.49 \pm 0.22$ vs. $0.68 \pm 0.17, \mathrm{P}<0.01)$ and in the 72 -h group $(2.44 \pm 0.22$ vs. $0.97 \pm 0.35, P<0.01 ; 3.62 \pm 0.37$ vs. $0.97 \pm 0.35, \mathrm{P}<0.01)$. The effects of TRD on the upregulation of GRIM-19 protein expression appeared to be dose-dependent (Fig. 2A-C).

The mRNA expression levels of GRIM-19 mRNA in the different groups were detected by RT-qPCR. TRD treatment (100 and $200 \mu \mathrm{M}$ ) significantly enhanced GRIM-19 mRNA expression in HepG2 cells in the 24-h group $(0.93 \pm 0.07$ vs. $0.36 \pm 0.05, \mathrm{P}<0.01 ; 1.14 \pm 0.11$ vs. $0.36 \pm 0.05, \mathrm{P}<0.01)$, in the 48 -h group $(1.12 \pm 0.14$ vs. $0.44 \pm 0.06, \mathrm{P}<0.01 ; 1.39 \pm 0.21$ 


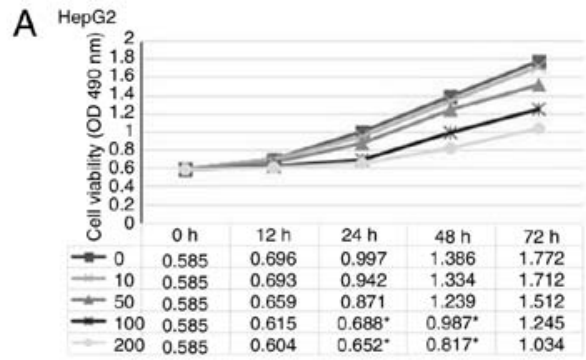

B
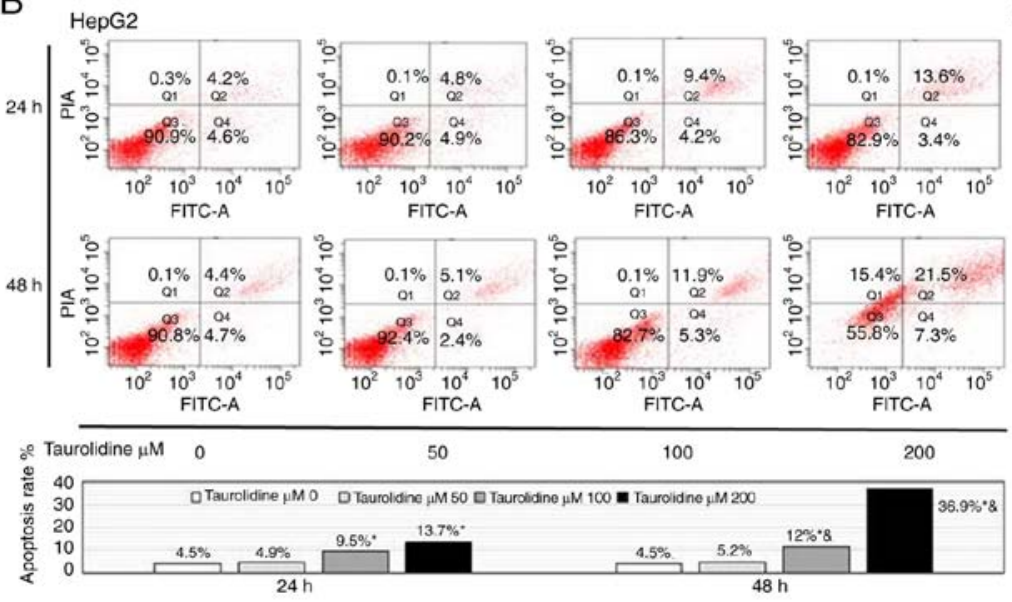

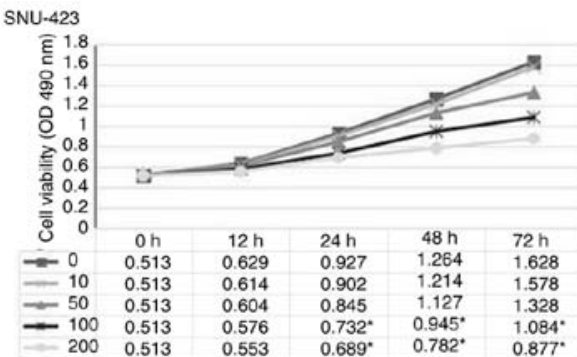

SNU-423

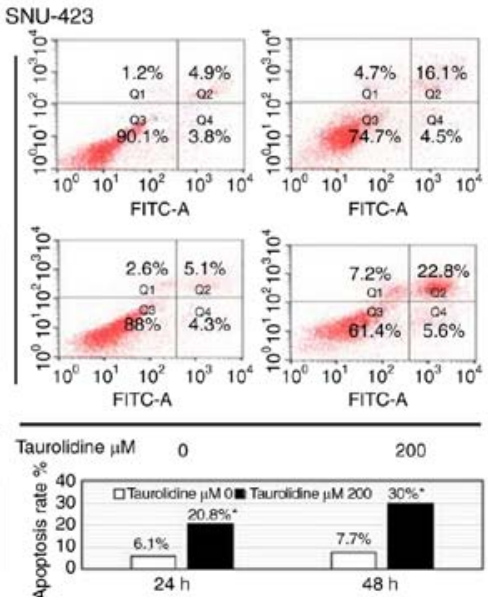

Figure 1. TRD significantly reduces HepG2 and SNU-423 cell viability, and induces apoptosis. (A) Cells were treated with various concentrations of TRD $(10,50,100$ and $200 \mu \mathrm{M})$ for $0,12,24,48$ or $72 \mathrm{~h}$. Cell viability of the different groups was determined by the MTT assay. (B) HepG2 cells were treated with various concentrations of TRD $(50,100$ and $200 \mu \mathrm{M})$ for 24 or $48 \mathrm{~h}$ and cell apoptosis was analyzed by flow cytometry. SNU-423 cells were treated with $200 \mu \mathrm{M}$ TRD for 24 or $48 \mathrm{~h}$ to observe cell apoptosis by flow cytometry. Data are representative images or expressed as the means \pm standard deviation of three separate experiments. $\mathrm{P}<0.05$ compared with the control group. ${ }^{\&} \mathrm{P}<0.05$ compared with the $24 \mathrm{~h}$ group. OD, optical density; TRD, taurolidine.

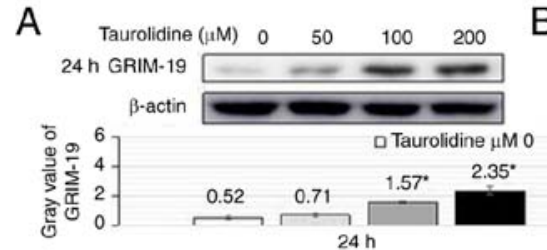

D

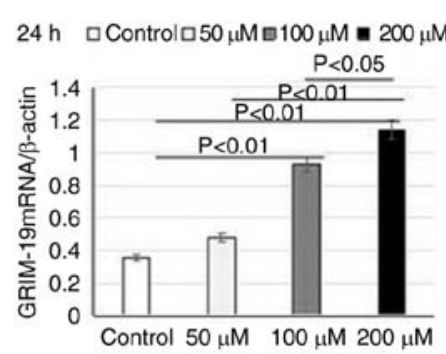

G

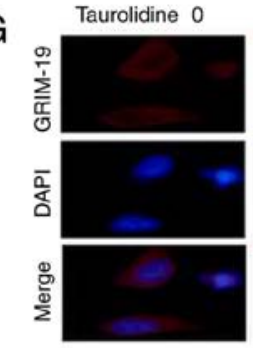

B

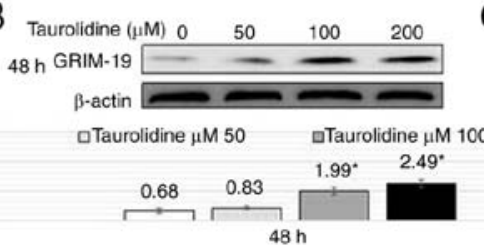

E

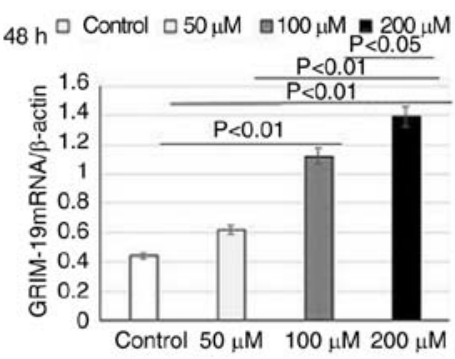

50

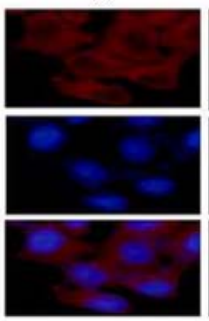

100

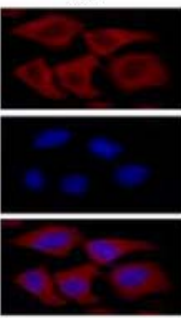

C Taurolidine $(\mu \mathrm{M}) 0 \quad 50 \quad 100 \quad 200$

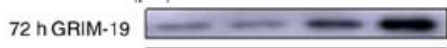

$\beta$-actin

- Taurolidine $\mu \mathrm{M} 200$

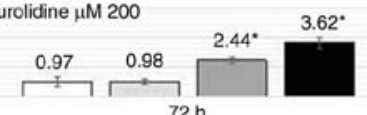

$\mathrm{F}$

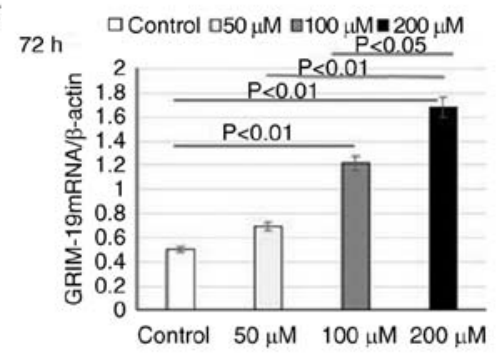

200

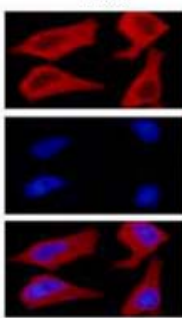

Figure 2. TRD upregulates GRIM-19 expression in HepG2 cells. HepG2 cells were treated with TRD at various concentrations $(50,100$ and $200 \mu \mathrm{M})$ for 24, 48 or $72 \mathrm{~h}$. (A-C) Protein expression level of GRIM-19 were detected in TRD-treated HepG2 cells by western blot analysis. (D-F) TRD treatment enhanced GRIM-19 mRNA expression in HepG2 cells. (G) HepG2 cells were cultured on glass cover slips and stained with anti-GRIM-19 and tetramethyl rhodamine isothiocyanate-conjugated secondary antibodies, followed by counterstaining with DAPI. GRIM-19 expression was characterized under a fluorescence microscope. Data are representative images (magnification, $\mathrm{x} 400$ ) or are expressed as the means \pm standard deviation of three separate experiments. ${ }^{*} \mathrm{P}<0.05$ compared with the control group. GRIM-19, retinoic-interferon-induced mortality 19; TRD, taurolidine. 

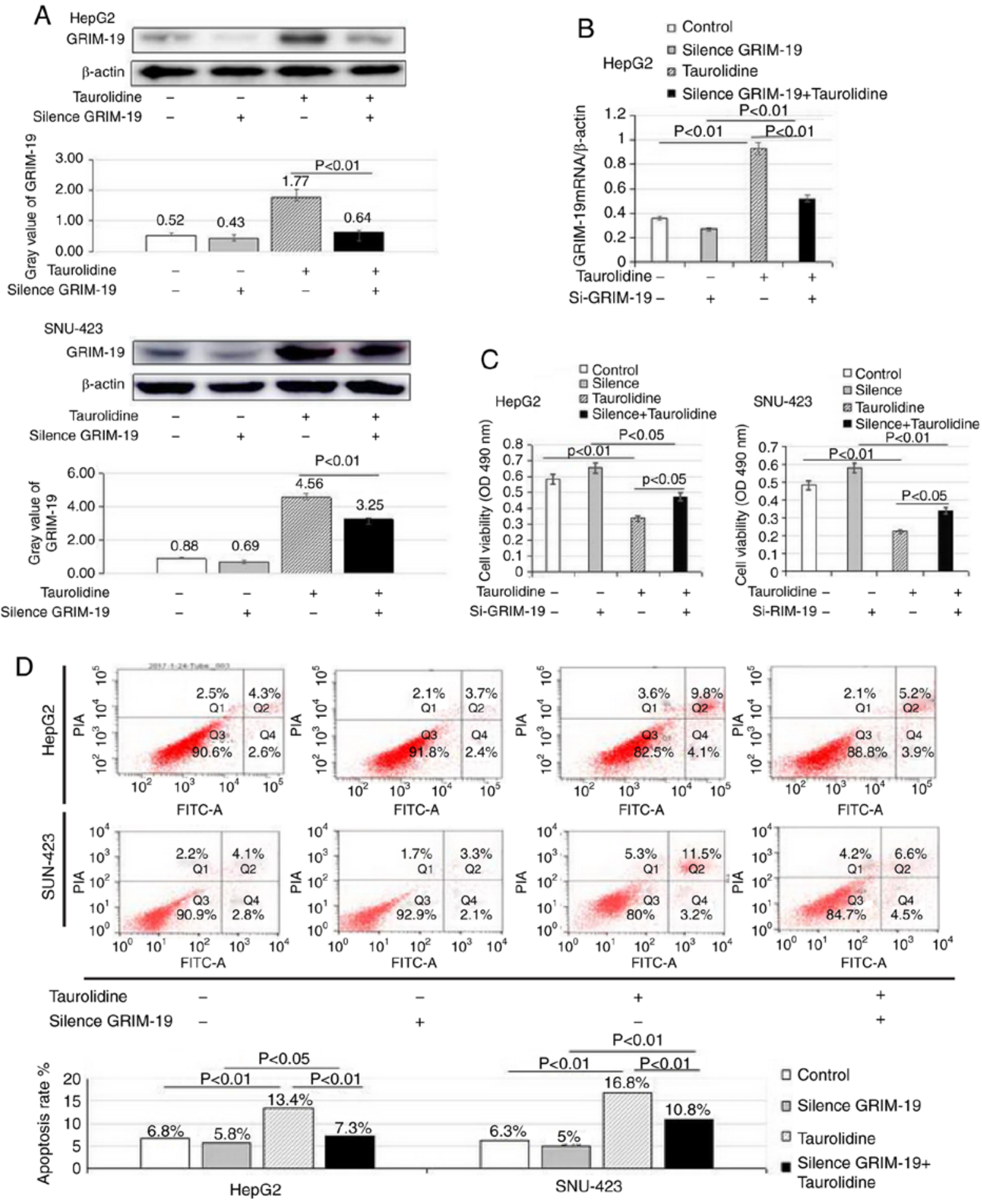

$+$

$+$

Figure 3. GRIM-19 serves a critical role in TRD-induced inhibition of viability and enhanced apoptosis in HepG2 cells and SNU-423 cells. Post-transfection with GRIM-19 or control siRNA for $24 \mathrm{~h}$, cells were treated with TRD for $24 \mathrm{~h}$. (A) GRIM-19 protein expression in the four groups of HepG2 and SNU-423 cells. (B) GRIM-19 mRNA expression in the four groups. (C and D) Effects of GRIM-19 siRNA transfection on cell viability and apoptosis of TRD-treated HepG2 cells and SNU-423 cells. GRIM-19, retinoic-interferon-induced mortality 19; OD, optical density; siRNA, small interfering RNA; TRD, taurolidine.

vs. $0.44 \pm 0.06, \mathrm{P}<0.01)$ and in the 72 -h group $(1.22 \pm 0.22$ vs. $0.5 \pm 0.09, \mathrm{P}<0.01 ; 1.68 \pm 0.25$ vs. $0.5 \pm 0.09, \mathrm{P}<0.01)($ Fig. $2 \mathrm{D}-\mathrm{F})$.

Our previous study revealed that GRIM-19 is predominantly expressed in the cytoplasm of liver cancer tissue slices, whereas its expression in nuclei is limited (19). To confirm this observation in HepG2 cells, the cellular localization of endogenous GRIM-19 was analyzed by immunofluorescence. Consistent with the histological staining results of our previous study, GRIM-19 expression was detected in the cytoplasm, and its expression was markedly increased in the presence of TRD (Fig. 2G).

GRIM-19 serves a critical role in TRD-induced inhibition of viability and promotion of apoptosis in liver cancer cells. To determine the effects of GRIM-19 on the viability and apoptosis of liver cancer cells, GRIM-19 expression was knocked 
A

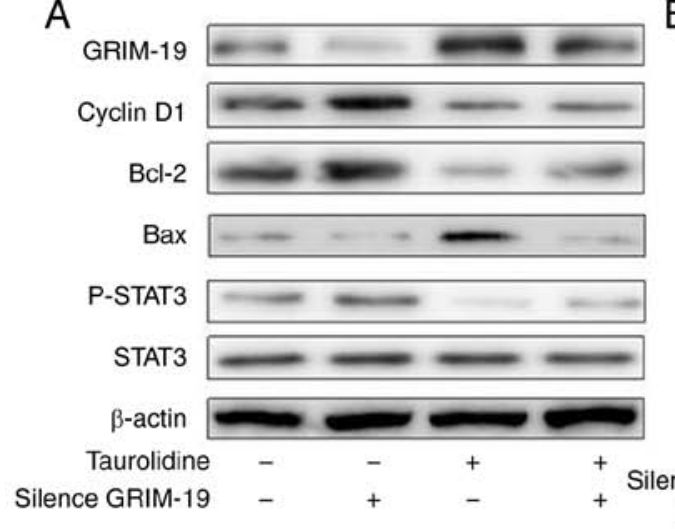

B

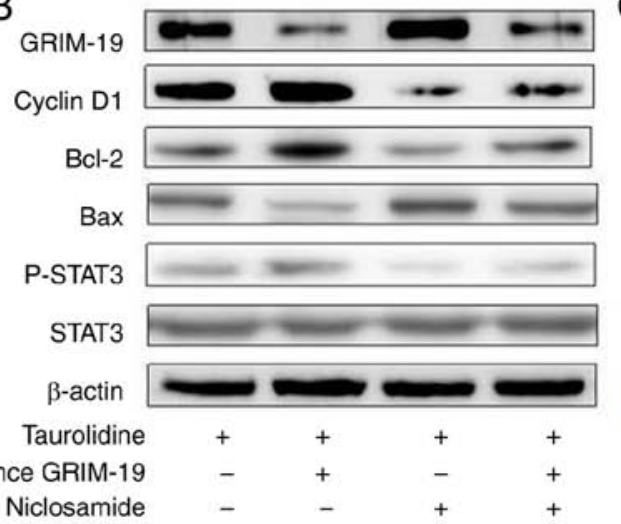

C

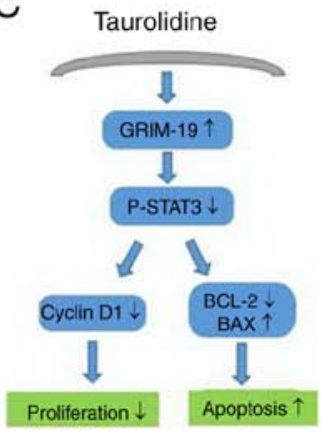

Figure 4. GRIM-19 regulates HepG2 cell proliferation and apoptosis via a STAT3-dependent pathway. The expression levels of proliferation- and apoptosis-associated molecules, STAT3, p-STAT3, cyclin D1, Bcl-2 and Bax, were detected by western blotting. (A) Expression of p-STAT3, cyclin D1 and Bcl-2 was increased, and that of Bax was decreased, in the GRIM-19 siRNA group, whereas TRD treatment had the opposite effect, inhibiting the expression of p-STAT3, cyclin D1 and Bcl-2, and increasing that of Bax, compared with the control group. (B) High expression levels of GRIM-19 and Bax were detected in the TRD and TRD + niclosamide groups, which were accompanied by low levels of cyclin D1, Bcl-2 and-STAT3. Conversely, low expression levels of GRIM-19 and Bax, and high expression levels of cyclin D1, Bcl-2 and p-STAT3 were detected in the TRD+GRIM-19 siRNA group. (C) Schematic diagram. Data are representative images or expressed as the means \pm standard deviation of each group from three separate experiments. Bax, Bcl-2-associated $\mathrm{X}$ protein; Bcl-2, B-cell lymphoma 2; GRIM-19, retinoic-interferon-induced mortality 19; p-STAT3, phosphorylated-STAT3; siRNA, small interfering RNA; STAT3, signal transducer and activator of transcription 3; TRD, taurolidine.

down by RNA interference in HepG2 and SNU-423 cells. Post-transfection with GRIM-19 siRNA or control siRNA for $24 \mathrm{~h}$, the cells were treated with $100 \mu \mathrm{M}$ TRD for $24 \mathrm{~h}$. As shown in Fig. 3A and B, the protein and mRNA expression levels of GRIM-19 were significantly decreased in the TRD + GRIM-19 siRNA group compared with in the TRD treatment group (protein: $0.64 \pm 0.06$ vs. $1.77 \pm 0.25, \mathrm{P}<0.01$; mRNA: $0.52 \pm 0.04$ vs. $0.93 \pm 0.17, \mathrm{P}<0.01$ ). However, there was no significant difference between the GRIM-19 siRNA and control groups (protein: $0.43 \pm 0.11$ vs. $0.52 \pm 0.09, \mathrm{P}=0.23$; mRNA: $0.27 \pm 0.08$ vs. $0.36 \pm 0.03, \mathrm{P}=0.25$ ). This may be related to the weak expression of GRIM-19 in the control group. Furthermore, GRIM-19 protein and mRNA expression were significantly increased in the TRD treatment group compared with in the control group.

As shown in Fig. 3C, TRD, which is an inducer of GRIM-19, significantly inhibited HepG2 cell viability compared with in the control group $(0.339 \pm 0.09$ vs. $0.585 \pm 0.13, \mathrm{P}<0.01)$. Conversely, the effects of TRD on cell viability were reversed following GRIM-19 knockdown $(0.339 \pm 0.09$ vs. $0.472 \pm 0.1, \mathrm{P}<0.05)$; however, cell viability was not completely recovered. Similar findings were observed in SNU-423 cells. There may be other molecular mechanisms participating in the regulation of TRD in liver cancer cell viability. Taken together, these findings suggested that GRIM-19 was involved in the regulation of cell viability.

As shown in Fig. 3D, flow cytometry revealed that TRD treatment increased the percentage of apoptotic cells compared with control siRNA transfection $(\mathrm{P}<0.01)$. Cell apoptosis was significantly inhibited in the GRIM-19 siRNA + TRD group compared with in the TRD group $(\mathrm{P}<0.01)$ and the percentage of apoptotic cells was increased compared with the GRIM-19 siRNA group $(\mathrm{P}<0.05)$. Cell apoptosis in the TRD treatment group was the highest observed among the four groups. In addition, there was no significant difference in cell apoptosis between the GRIM-19 siRNA and control siRNA groups $(\mathrm{P}=0.13)$.

GRIM-19 regulates HepG2 cell proliferation and apoptosis via a STAT3-dependent pathway. To clarify the mechanism underlying the effects of TRD and GRIM-19 on cell viability and apoptosis, the expression of proliferation- and apoptosis-associated molecules, including STAT3, p-STAT3, cyclin D1, Bcl-2 and Bax, was detected by western blotting. As shown in Fig. 4A, the expression levels of p-STAT3, cyclin D1 and Bcl-2 were increased in the GRIM-19 siRNA group, whereas those of Bax were decreased. TRD treatment was revealed to have the opposite effect, inhibiting the expression of p-STAT3, cyclin D1 and Bcl-2, and increasing that of Bax, compared with the control group. These results suggested that GRIM-19 regulated HepG2 cell viability and apoptosis through the STAT3 pathway.

To further confirm the role of the STAT3 signaling pathway in TRD treatment, GRIM-19 knockdown cells were pretreated with a p-STAT3 inhibitor, niclosamide, for $30 \mathrm{~min}$, and $100 \mu \mathrm{M}$ TRD was then added for $24 \mathrm{~h}$. Western blot analysis detected high GRIM-19 and Bax expression in the TRD and TRD + niclosamide groups, accompanied by low expression levels of cyclin D1, Bcl-2 and p-STAT3. Conversely, low expression levels of GRIM-19 and Bax, and high expression levels of cyclin D1, Bcl-2 and p-STAT3 were detected in the TRD + GRIM-19 siRNA group. Niclosamide reduced the expression of p-STAT3, cyclin D1 and Bcl-2, and increased that of Bax, in the TRD-treated HepG2 cells, irrespective of GRIM-19 knockdown. However, there was no effect on the expression levels of GRIM-19, irrespective of the addition of niclosamide (Fig. 4B). This phenomenon indicated that GRIM-19 was an upstream molecule of the STAT3 signaling pathway. These findings suggested that TRD may enhance GRIM-19 expression and induce apoptosis of human liver cancer cells via a STAT3-dependent pathway. 


\section{Discussion}

TRD is one of the most common types of human cancer, and a leading cause of cancer-associated mortality worldwide. Statistics have demonstrated that the majority of patients with liver cancer are not suitable for surgical resection, thus carrying a considerably poor prognosis. Particularly in patients with advanced liver cancer, the benefits of conventional therapy are limited; therefore, the need for more effective systemic treatments is urgent. TRD is an antiseptic agent derived from the amino sulfonic acid taurine, which has been used to treat peritonitis and catheter-associated infections (5). Recently, TRD has been used to treat malignant diseases (33-36), including gastrointestinal carcinoma, glioblastoma, fibrosarcoma, prostate cancer and melanoma (34,36-39). However, its precise mechanism of action remains unclear. In the present study, treatment with TRD significantly inhibited the viability and triggered the apoptosis of liver cancer cells.

In our previous study (19), it was revealed that GRIM-19 expression is reduced in liver cancer compared with in adjacent liver tissue. Furthermore, the decreased expression of GRIM-19 in liver cancer lesions is closely associated with an increased histological grading in liver cancer. In the present study, treatment with TRD significantly increased GRIM-19 expression in the cytoplasm of HepG2 cells. Simultaneously, cell viability was inhibited, whereas apoptosis was induced in TRD-treated HepG2 and SNU-423 cells, accompanied by an increase in GRIM-19 expression. In addition, the viability and apoptosis of HepG 2 and SNU-423 cells, which had been affected by TRD treatment, was recovered when GRIM-19 was knocked down. These findings indicated that TRD inhibited cell viability and induced apoptosis via the GRIM-19 pathway in TRD. Wei et al (32) revealed that GRIM-19 is predominantly expressed in the nuclei of HeLa cells. Haura et al (40) reported that GRIM-19 is predominantly expressed in the inner mitochondrial membrane and is a component of the mitochondrial complex I. In the present study, it was revealed that GRIM-19 was predominantly expressed in the cytoplasm of liver cancer cells, which is consistent with our previous results (19).

The aim of the present study was to expand the investigation of the in vitro effects of TRD treatment on cell apoptosis. The apoptotic mechanism of cancer cells is composed of both upstream regulators and downstream effector components. The regulators can be divided into two major circuits. One receives and processes extracellular death-inducing signals, and the other senses and integrates various signals of intracellular origin. Bcl-2 is an upstream effector molecule in the apoptotic pathway, which has been identified as a potent suppressor of apoptosis. Bcl-2 has been reported to form a heterodimer complex with the proapoptotic Bax, thereby neutralizing its proapoptotic effects. Therefore, the ratio of $\mathrm{Bax} / \mathrm{Bcl}-2$ is a decisive factor and serves an important role in determining whether cells die or survive (41-44). The expression levels of these proteins were detected by western blot analysis in the present study, in order to determine their involvement in the molecular mechanisms underlying the role of TRD in liver cancer cell apoptosis.

Our previous study detected a significantly higher nuclear expression of p-STAT3 in liver cancer lesions. Notably, an inverse correlation was identified between GRIM-19 and p-STAT3 expression in liver cancer tissues (19). To verify this mechanism in vitro, a p-STAT3 inhibitor (niclosamide) was added and the expression of proliferation- and apoptosisassociated molecules, STAT3, p-STAT3, cyclin D1, Bcl-2 and Bax, was detected by western blotting. The result demonstrated that treatment with TRD not only enhanced the expression of GRIM-19, but also reduced the expression of cyclin D1, Bcl-2 and p-STAT3 in HepG2 cells. This result further supported the hypothesis that TRD may induce the apoptosis of human liver cancer cells through GRIM-19-induced regulation of a STAT3-dependent pathway. The present data demonstrated that niclosamide reduced the expression levels of p-STAT3, cyclin D1 and Bcl-2, and increased those of Bax in TRD-treated HepG2 cells, irrespective of GRIM-19 knockdown. This phenomenon indicated that GRIM-19 may be an upstream molecule of the STAT3 signaling pathway.

In conclusion, the present study indicated that GRIM-19 was predominantly expressed in the cytoplasm of liver cancer cells, and the knockdown of GRIM-19 was accompanied by an increase in the expression of cyclin D1, Bcl-2 and p-STAT3 in these cells. As shown in Fig. 4C, treatment with TRD significantly upregulated GRIM-19 expression, but downregulated cyclin D1, Bcl-2 and p-STAT3 expression in HepG2 cells and SNU-423 cells. However, these expression levels were recovered following GRIM-19 knockdown. In summary, TRD inhibited liver cancer cell viability and induced apoptosis via GRIM-19-induced regulation of a STAT3-dependent pathway; therefore, TRD may serve as a novel effective treatment for liver cancer.

\section{Acknowledgements}

Not applicable.

\section{Funding}

This study was supported in part by grants from the Shandong Province Medical and Health Science and Technology Development Project (grant no. 2017WS465), the National Natural Science Foundation of China (grant $n$ os. 81600469 and 81472685), the Science and Technology Development Projects of Shandong Province (grant nos. 20 17GSF218053 and 2016GSF201126), and the Major Special Plan of Science and Technology of Shandong Province (grant no. 2015ZDXX0802A01).

\section{Availability of data and materials}

The datasets used and/or analyzed during the current study are available from the corresponding author on reasonable request.

\section{Authors' contributions}

FL contributed to experimentation and manuscript writing. JQ was responsible for technical guidance and data interpretation. CQ was responsible for data analysis and statistical analysis. ZF and WR made substantial contributions to conception and design. All authors read and approved the final manuscript. 


\section{Ethics approval and consent to participate}

Not applicable.

\section{Patient consent for publication}

Not applicable.

\section{Competing interests}

The authors declare that they have no competing interests.

\section{References}

1. Chen W, Zheng R, Baade PD, Zhang S, Zeng H, Bray F, Jemal A, Yu XQ and He J: Cancer statistics in China, 2015. CA Cancer J Clin 66: 115-132, 2016.

2. Mittal S and El-Serag HB: Epidemiology of hepatocellular carcinoma: Consider the population. J Clin Gastroenterol 47 (Suppl): S2-S6, 2013

3. Pinter M, Trauner M, Peck-Radosavljevic M and Sieghart W: Cancer and liver cirrhosis: Implications on prognosis and management. ESMO Open 1: e000042, 2016.

4. Kanda T, Ogasawara S, Chiba T, Haga Y, Omata M and Yokosuka O: Current management of patients with hepatocellular carcinoma. World J Hepatol 7: 1913-1920, 2015.

5. Chromik AM, Daigeler A, Bulut D, Flier A, May C, Harati K, Roschinsky J, Sülberg D, Ritter PR, Mittelkötter U, et al: Comparative analysis of cell death induction by Taurolidine in different malignant human cancer cell lines. J Exp Clin Cancer Res 29: 21, 2010.

6. Stendel R, Stoltenburgdidinger G, Al Keikh CL, Wattrodt M and Brock M: The effect of taurolidine on brain tumor cells. Anticancer Res 22: 809-814, 2002.

7. Stendel R, Biefer HR, Dékány GM, Kubota H, Münz C, Wang S, Mohler H, Yonekawa Y and Frei K: The antibacterial substance taurolidine exhibits anti-neoplastic action based on a mixed type of programmed cell death. Autophagy 5: 194-210, 2009.

8. Braumann C, Jacobi CA, Rogalla S, Menenakos C, Fuehrer K, Trefzer $U$ and Hofmann M: The tumor suppressive reagent taurolidine inhibits growth of malignant melanoma-a mouse model. J Surg Res 143: 372-378, 2007.

9. Sun BS, Wang JH, Liu LL, Gong SL and Redmond HP. Taurolidine induces apoptosis of murine melanoma cells in vitro and in vivo by modulation of the Bcl-2 family proteins. J Surg Oncol 96: 241-248, 2007

10. Opitz I, Sigrist B, Hillinger S, Lardinois D, Stahel R, Weder W and Hopkins-Donaldson S: Taurolidine and povidone-iodine induce different types of cell death in malignant pleural mesothelioma. Lung Cancer 56: 327-336, 2007.

11. Aceto N, Bertino P, Barbone D, Tassi G, Manzo L, Porta C, Mutti L and Gaudino G: Taurolidine and oxidative stress: A rationale for local treatment of mesothelioma. Eur Respir J 34: 1399-1407, 2009.

12. Braumann C, Schoenbeck M, Menenakos C, Kilian M and Jacobi CA: Effects of increasing doses of a bolus injection and an intravenous long-term therapy of taurolidine on subcutaneous (metastatic) tumor growth in rats. Clin Exp Metastasis 22 77-83, 2005.

13. Chromik AM, Daigeler A, Hilgert C, Bulut D, Geisler A, Liu V, Otte JM, Uhl W and Mittelkötter U: Synergistic effects in apoptosis induction by taurolidine and TRAIL in HCT-15 colon carcinoma cells. J Invest Surg 20: 339-348, 2007.

14. Daigeler A, Chromik AM, Geisler A, Bulut D, Hilgert C, Krieg A, Klein-Hitpass L, Lehnhardt M, Uhl W and Mittelkötter U: Synergistic apoptotic effects of taurolidine and TRAIL on squamous carcinoma cells of the esophagus. Int J Oncol 32: 1205-1220, 2008.

15. Walters DK, Muff R, Langsam B, Gruber P, Born W and Fuchs B: Taurolidine: A novel anti-neoplastic agent induces apoptosis of osteosarcoma cell lines. Invest New Drugs 25: 305-312, 2007.

16. Daigeler A, Brenzel C, Bulut D, Geisler A, Hilgert C,Lehnhardt M, Steinau HU, Flier A, Steinstraesser L, Klein-Hitpass L, et al: TRAIL and Taurolidine induce apoptosis and decrease proliferation in human fibrosarcoma. J Exp Clin Cancer Res 27: 82, 2008
17. Chidambaram NV, Angell JE, Ling W, Hofmann ER and Kalvakolanu DV: Chromosomal localization of human GRIM-19, a novel IFN-beta and retinoic acid-activated regulator of cell death. J Interferon Cytokine Res 20: 661-665, 2000.

18. Chen Y, Lu H, Liu Q, Huang G, Lim CP, Zhang L, Hao A and Cao X: Function of GRIM-19, a mitochondrial respiratory chain complex I protein, in innate immunity. J Biol Chem 287: 27227-27235, 2012.

19. Li F, Ren W, Zhao Y, Fu Z, Ji Y,Zhu Y and Qin C: Downregulation of GRIM-19 is associated with hyperactivation of p-STAT3 in hepatocellular carcinoma. Med Oncol 29: 3046-3054, 2012.

20. Zhao J, Nie W, Li W, Zhou X, Sun H, Zhu J, Chen J and Peng J: Interferon- $\beta$ combined with all-trans retinoic acid supresses proliferation and promote apoptosis by inhibiting JAK2/STAT3 pathway in HepG2 human hepatocellular carcinoma cells. Xi Bao Yu Fen Zi Mian Yi Xue Za Zhi 32: 901-905, 2016 (In Chinese).

21. Gong L, Greenberg HE, Perhach JL, Waldman SA and Kraft WK: The pharmacokinetics of taurolidine metabolites in healthy volunteers. J Clin Pharmacol 47: 697-703, 2007.

22. Braumann C, Winkler G, Rogalla P, Menenakos C and Jacobi CA: Prevention of disease progression in a patient with a gastric cancer-re-recurrence. Outcome after intravenous treatment with the novel antineoplastic agent taurolidine. Report of a case. World J Surg Oncol 4: 34, 2006.

23. Stendel R, Picht T, Schilling A, Heidenreich J, Loddenkemper C, Jänisch W and Brock M: Treatment of glioblastoma with intravenous taurolidine. First clinical experience. Anticancer Res 24: 1143-1147, 2004

24. Stendel R, Scheurer L, Schlatterer K, Stalder U, Pfirrmann RW, Fiss I, Möhler H and Bigler L: Pharmacokinetics of taurolidine following repeated intravenous infusions measured by HPLC-ESI-MS/MS of the derivatives taurultame and taurinamide in glioblastoma patients. Clin Pharmacokinet 46: 513-524, 2007.

25. Darnowski JW, Goulette FA, Cousens LP, Chatterjee D and Calabresi P: Mechanistic and antineoplastic evaluation of taurolidine in the DU145 model of human prostate cancer. Cancer Chemother Pharmacol 54: 249-258, 2004.

26. Han Z, Ribbizi I, Pantazis P, Wyche J, Darnowski J and Calabresi P: The antibacterial drug taurolidine induces apoptosis by a mitochondrial cytochrome $c$-dependent mechanism. Anticancer Res 22: 1959-1964, 2002.

27. Rodak R, Kubota H, Ishihara H, Eugster HP, Könü D, Möhler H, Yonekawa $\mathrm{Y}$ and Frei K: Induction of reactive oxygen intermediates-dependent programmed cell death in human malignant ex vivo glioma cells and inhibition of the vascular endothelial growth factor production by taurolidine. J Neurosurg 102: 1055-1068, 2005.

28. Stendel R, Scheurer L, Stoltenburg-Didinger G, Brock M and Möhler H: Enhancement of Fas-ligand-mediated programmed cell death by taurolidine. Anticancer Res 23: 2309-2314, 2003.

29. Kolligs FT, Nieman MT, Winer I, Hu G, Van Mater D, Feng Y, Smith IM, Wu R, Zhai Y, Cho KR, et al: ITF-2, a downstream target of the Wnt/TCF pathway, is activated in human cancers with beta-catenin defects and promotes neoplastic transformation. Cancer Cell 1: 145-155, 2002.

30. Ottaviano AJ, Sun L, Ananthanarayanan V and Munshi HG: Extracellular matrix-mediated membrane-type 1 matrix metalloproteinase expression in pancreatic ductal cells is regulated by transforming growth factor-beta1. Cancer Res 66: 7032-7040, 2006.

31. Livak KJ and Schmittgen TD: Analysis of relative gene expression data using real-time quantitative PCR and the $2^{-\Delta \Delta C_{\mathrm{T}}}$ method. Methods 25: 402-408, 2001.

32. Wei D, Le X, Zheng L, Wang L, Frey JA, Gao AC, Peng Z, Huang S, Xiong HQ, Abbruzzese JL and Xie K: Stat 3 activation regulates the expression of vascular endothelial growth factor and human pancreatic cancer angiogenesis and metastasis. Oncogene 22: 319-329, 2003.

33. Jacobi CA, Menenakos $C$ and Braumann C: Taurolidine-a new drug with anti-tumor and anti-angiogenic effects. Anticancer Drugs 16: 917-921, 2005.

34. Mccourt M, Wang JH, Sookhai S and Redmond HP: Taurolidine inhibits tumor cell growth in vitro and in vivo. Ann Surg Oncol 7: 685-691, 2000.

35. Petrovic L, Schlegel KA, Ries J, Park J, Diebel E, Schultze-Mosgau $S$ and Wiltfang J: In vitro effect of taurolidine on squamous cell carcinoma in the oral cavity. Mund Kiefer Gesichtschir 7: 102-107, 2003 (In German). 
36. Gallagher KA, Liu ZJ, Xiao M, Chen H, Goldstein LJ, Buerk DG, Nedeau A, Thom SR and Velazquez OC: Diabetic impairments in NO-mediated endothelial progenitor cell mobilization and homing are reversed by hyperoxia and SDF-1. J Clin Invest 117: 1249-1259, 2007.

37. Calabresi P, Goulette FA and Darnowski JW: Taurolidine: Cytotoxic and mechanistic evaluation of a novel antineoplastic agent. Cancer Res 61: 6816-6821, 2001.

38. Braumann C, Henke W, Jacobi CA and Dubiel W: The tumor-suppressive reagent taurolidine is an inhibitor of protein biosynthesis. Int J Cancer 112: 225-230, 2004.

39. Neary PM, Hallihan P, Wang JH, Pfirrmann RW, Bouchier-Hayes DJ and Redmond HP: The evolving role of taurolidine in cancer therapy. Ann Surg Oncol 17: 1135-1143, 2010.
40. Haura EB, Turkson J and Jove R: Mechanisms of disease: Insights into the emerging role of signal transducers and activators of transcription in cancer. Nat Clin Pract Oncol 2: 315-324, 2005.

41. Oltvai ZN, Milliman CL and Korsmeyer SJ: Bcl-2 heterodimerizes in vivo with a conserved homolog, Bax, that accelerates programed cell death. Cell 74: 609-619, 1993.

42. Korsmeyer SJ, Shutter JR, Veis DJ, Merry DE and Oltvai ZN: Bcl-2/Bax: A rheostat that regulates an anti-oxidant pathway and cell death. Semin Cancer Biol 4: 327-332, 1993.

43. Tsukahara S, Yamamoto S, Tin-Tin-Win-Shwe, Ahmed S, Kunugita N, Arashidani K and Fujimaki H: Inhalation of low-level formaldehyde increases the $\mathrm{Bcl}-2 / \mathrm{Bax}$ expression ratio in the hippocampus of immunologically sensitized mice. Neuroimmunomodulation 13: 63-68, 2006.

44. Walensky LD: BCL-2 in the crosshairs: Tipping the balance of life and death. Cell Death Differ 13: 1339-1350, 2006. 